\title{
Evaluating Entrepreneurial Features of Firm's Growth Using Confirmatory Factor Analysis
}

\author{
Arthur-Aidoo B. M., Aigbavboa C., Thwala W. D. \\ Faculty of Engineering and the Built Environment, University of Johannesburg, South Africa \\ BERNARDMARTINS@hotmail.com,calgbavboa@uj.ac.za
}

\begin{abstract}
The growth of Small and medium-size firms cannot ensue without the entrepreneurial features and the environment that the firm operates. The entrepreneurial characteristics, therefore, are vital due to the unique individualism of firm owners or sponsors. Construction SME growth-oriented firms are a significant contributor to Ghana's economic gain. Conversely, the concept of growth varies from one entrepreneur to the others depending on the exhibited skills by the entrepreneurs, hence entrepreneurial features. Numerous factors influence the entrepreneurial features as a factor of firm's growth. Some are of the factors are established and categorised as having strong influence while others are classified weak. This study, therefore, adopted the confirmatory factor analytical technique to justify the factors after exploring. To achieve the goal of the study, respondents such as firm owners, SME managers and construction professionals engaged by SMEs as the population were administered with questionnaires. In all, 315 questionnaires were given out in the form of semi-structured structured, but only 228 were retrieved for analysis representing a responds rate of 72 percent. The study established Cronbach alpha and composite reliability values that predicted the entrepreneurial feature as a subsequent determinant of firm's growth. Additionally, the hypothesis was supported statistically suggesting that there is a direct relationship between entrepreneurial features and firm growth.
\end{abstract}

Keywords: Confirmatory Factor Analysis, entrepreneurial features, firm, growth

\section{Introduction}

Small and medium-size firms grow either by integration or organically (Miriam, 2006). Both of these growth conduits can ensue without the entrepreneurial features and the environment that the firm operates. These environments are categorised as internal and external. According to Islam et al. (2011), the internal environment factors comprise entrepreneurial management which consists of a level of emphasis placed on strategic direction, resources orientation, management structure entrepreneurial culture development, reward philosophy, and the entrepreneurial orientation is related to personal characteristics of the entrepreneurs. Entrepreneurial features depend on the characteristics of the person or persons that provide the key resources used in establishing the business. Zhou and Wit (2009) supported that the readiness and capability of the owner together with growth motivation suggest a significant role in entrepreneurial ventures. Similarly, Kritikos (2014) stressed that entrepreneurial features do not only manipulate the internal growth of a firm but also the economic growth of a country, suggesting that entrepreneurs usually develop new products, create new technologies, and open new markets that bring about growth in their firms and the entire economy. In the context of Ghana as the study area, entrepreneurial features which influence the growth of SMEs are not different from other Saharan African economies. In Ghana, most construction SMEs are branded of folding-up soon after the execution of major projects. Further, these SMEs are easily sprang-up leveraging on a single or one man ownership without any proper managerial structures and strategies that bring about growth. The small and medium-size construction (SMEs) in the Ghanaian construction sector are described as prolific job creators with the lack of growth traits. Also, construction SMEs in Ghana are also notable of been profit oriented without any model that will promote firm's growth.

Despite the significant constraints faced by the entire SME sector within the Ghanaian economy, the extreme and overwhelming benefits associated with the construction SMEs makes them unique. The SME sector in Ghana is thus a major employer in the economy coupled with their impact in the social and economic development which makes them indisputable. As a result, the activities of SMEs that proliferates growth both at the micro and macro-levels of the economy are considered vital. According to Keskin and Senturk (2010) recent empirical studies reveal that Small and medium-size firms contribute to the Gross Domestic Product (GDP) to over 55 percent and over 65 percent of the total employment in high-income countries. While in the middle-income economies, the contribution of SMEs is over 95 percent of total employment and about 70 percent of GDP. To continue achieving and contributing to this significant Key Performance Indicator (KPI) by 
the firms, the SMEs need support. Entrepreneurial features revolve on the input of the person or persons that provide the key resources used in setting up the company. These features are typically identifiable before developing the business and include a range of personal and behavioural uniqueness. Diverse factors influence the entrepreneurial features as a factor of firm's growth. However, some are of the factors are established and categorised as having strong influence while others are characterised as slightly weak. An indepth study that gives insight into factors that influence entrepreneurial features as determinants of firm's growth is therefore essential. This study, therefore, sought to confirm the explored factors of as a factor of growth amongst construction SMEs in Ghana. Further, the confirmed factors can act as a benchmark to provide a comprehensive understanding on how to firm's growth will be initiated during the start-up of businesses via entrepreneurial activities of in a firm. This study was also driven throughout by the assumption statement that there is a significant relationship between entrepreneurial features and growth of firm.

\section{Literature Review}

Determinates of SMEs growth: A study by Hashi and Kransnigi (2011), emphasised that determinants of SMEs growth are clustered into three separate categories including those related to the characteristics of the firm, the business environment that the firm operates and lastly those related to entrepreneurial features of the firm. These entrepreneurial features include strong ambition of owner to growth, owner's strong entrepreneurial personality, strong desire to produce high standards, good development of internal ideas, strong human factor capital amongst others. Growth and expansion of SMEs depend utterly on the motivation and aspiration of the owner of the firm personality behavior. Delmar and Wiklund (2008) pointed that the character trait of entrepreneurs is a key factor that affects motivation Zhou and Wit (2009) supported that preparedness and capacity of the owner with the addition of growth motivation play a substantial role in entrepreneurial ventures. According to (Wiklund et al., 2003), approach to growth depends on the expected consequences of growth and what the entrepreneur is contented managing (Cliff, 1998). Also, Cassar (2007) supported that financial gain has not been found to a wholly determinant of attitudes toward growth but other important non-economic outcomes exist, such as those around keeping control and independence, and the effect on employee well-being Wiklund et al., 2003). The presence of an entrepreneurial team has also been shown to influence positively firm growth (Ensley et al., 2002; Ruef et al., 2003). An important function of SME's entrepreneurial is their ability to innovate and challenge incumbents firms with their creative products service offerings (Shane, 2003).

Table 1: Entrepreneurial Features as a factor of firm's growth with its sub-constructs influencing the factor

\begin{tabular}{|c|c|c|c|}
\hline Item & $\begin{array}{l}\text { Factor } \\
\text { growth }\end{array}$ driving $\quad$ Firm's & Code & Sub-constructs influencing factor of firm's growth \\
\hline & $\begin{array}{l}\text { Entrepreneurial Features of } \\
\text { firm (EFF) }\end{array}$ & $\begin{array}{l}\text { EFF } 1 \\
\text { EFF } 2 \\
\text { EFF } 3 \\
\text { EFF } 4 \\
\text { EFF } 5 \\
\text { EFF } 6 \\
\text { EFF } 7 \\
\text { EFF } 8 \\
\text { EFF } 9\end{array}$ & $\begin{array}{l}\text { Strong ambition of owner to growth } \\
\text { Owner's strong entrepreneurial personality } \\
\text { Strong desire to produce high standards } \\
\text { Good development of internal ideas } \\
\text { Strong human factor capital } \\
\text { High level of skill amongst employees } \\
\text { High worker motivation } \\
\text { High level of managers competencies } \\
\text { Exceptional level of education of entrepreneurs }\end{array}$ \\
\hline
\end{tabular}

Goedhuys and Veugelers (2012) stress that combining product and process innovation is vital for significantly improving the success and growth of SMEs. Accordingly, businesses owned by entrepreneurial teams have a more diversified and skilled resource base and a wider network of contacts, leading them to exploit business opportunities more efficiently hence better performance. Although general economic conditions are favourable, and firm may be able to exploit the growth in the market for the use of its resource capabilities, manager's ability and managerial ambition plays a reinforcing effect on the firm growth (Gopinath, 2012). Pajarinen et al. (2006) stressed that entrepreneurs with the higher academic profile are more innovative and will employ modern techniques and models to do business. Barringer and Bluedorn 
(1999) also described entrepreneurs as individuals who can explore the environment, discover the opportunities, and exploit them after proper evaluation. Literature has also acknowledged that individuals from families owning a business are more inclined to start an entrepreneurial venture by developing knowledge of how to run a business. Empirical evidence suggests that firms belonging to an entrepreneurial family augment the probability of survival (Cooper et al., 1994, Papadaki et al., 2000). However, firm's performance is found to be positively affected by the prior entrepreneurial experience Table (1).

Figure 1: Conceptual Framework for firm's growth

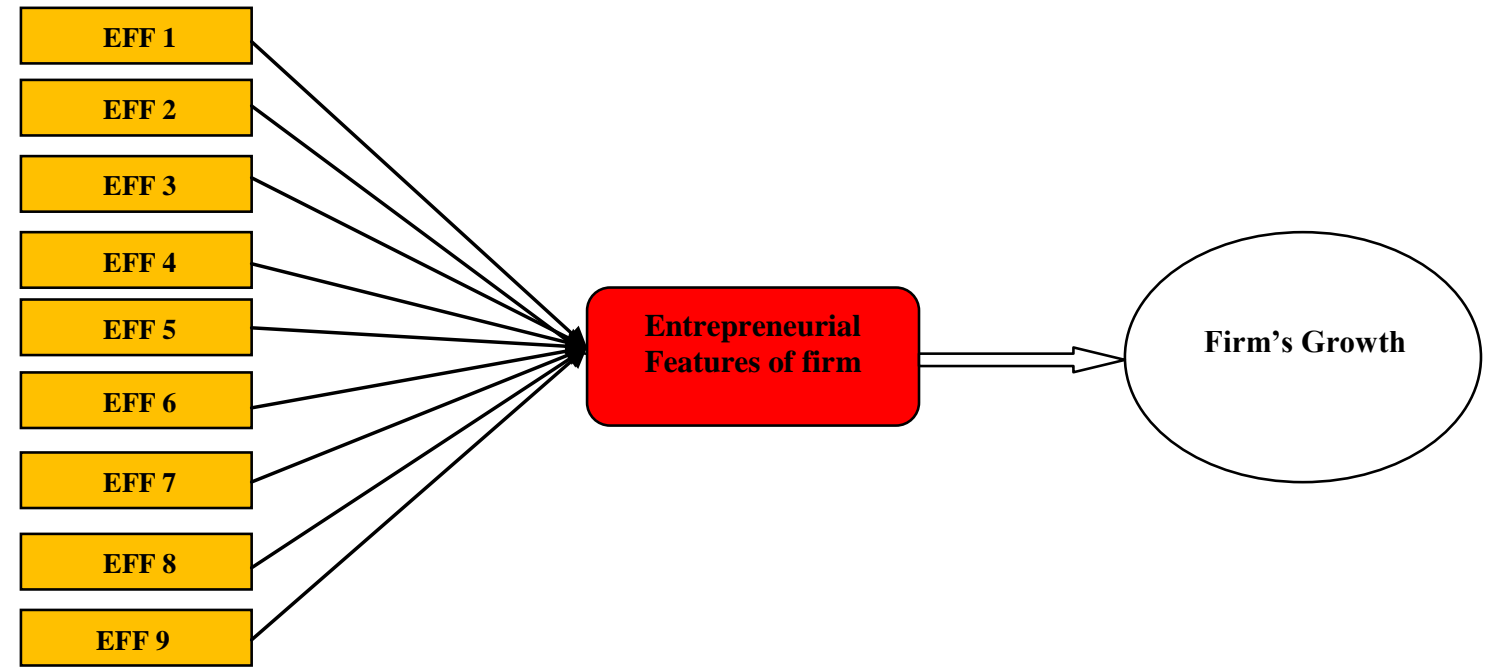

\section{Methodology}

This study used quantitative methodological approach, where survey questionnaires in a semi-structure format were administered to a targeted population comprising of firm owners, managers and construction professionals engaged by the construction SMEs. A total of 315 questionnaires were administered to construction SMEs throughout the entire regional capitals of Ghana, but only 228 was retrieved for analysis representing a response rate of 72 percent. The questionnaire adopted 5 points Likert-scale comprising a range of strongly influential to not at all influential. To ease the analysis of the collated data and further aid in addressing the goal of the study, sequential process including coding the responses, cleaning, screening the data and selecting the suitable data analysis technique, etc. was done. The selection of the suitable statistical analysis technique for this study was done considering the research objectives, and problem, the characteristics of the data and the underlying properties of the statistical technique as recommended by Malhotra (1999). To address the primary aim of the study, inferential analysis SPSS version 23 was accordingly used. The method commenced with Exploratory Factor Analysis (EFA) which first explored the factors which influenced entrepreneurial features as a driver of firm's growth. This was followed by the Confirmatory Factor Analysis (CFA) using the response of the questionnaires from the factors of firm's growth as depicted on Table (1). Prior the CFA test and the hypothesis for the study, the reliability and the validity of the study's construct were as well carried out.

\section{Analysis and Results}

Exploratory Factor Analysis: Before the used of the Confirmatory Factor Analysis, Exploratory factor analysis techniques were utilized to check the interrelationships among a set of variables which constituted and further influence entrepreneurial features a factor of firm's growth for the study. The statistical package for social sciences (SPSS) version 23 was used to evaluate the Kaiser-Mayor Olkine and Bartlett's test. Factor analysis is deemed appropriate when the Kaiser-Meyer-Olkin (KMO) the measure of sampling adequacy test index is higher than the satisfactory minimum limit of 0.5 and a desirable limit as 0.8 or greater (Kaiser, 1970). Hair et al. (2010) also suggested a cut-off value KMO greater than or equal to 0.07 . According to Hair et al. (2010), Bartlett's test with a significance level of less than 0.0001 substantiates the appropriateness of the 
factor model. Also, Eigenvalues were also used to confirm the factors within the proposed items. The eigenvalues greater than one were considered significant and it explained the variance obtained by a factor. This was, however, in-line with Hair et al. (2010) assertion that, eigenvalues of less than one are considered insignificant, these were excluded accordingly in the current study. Following the subjection of the factors through the EFA analytical test, the respective KOM values and the significance level are summarised in Table 2. The significant level was less than 0.05 , representing that the correlation matrix is significantly dissimilar from an identity matrix in which the correlations between variables are all zero. Also, the Kaiser-Meyer-Olkin Measure of Sampling Adequacy (KMO) was greater than 0.70 which indicates sufficient items for each factor.

Table 2: Factors of firm's growth with KMO and Significance Level

\begin{tabular}{ccccc}
\hline Construct & CODE & $\begin{array}{l}\text { Number of Items } \\
\text { extracted }\end{array}$ & KMO & Significance level \\
\hline & EFF 2 & & & \\
EFF 3 & 3 & 0.791 & 0.000 \\
\hline
\end{tabular}

Source: Author's Compilation

Entrepreneurial features (EFF) of a firm as an independent variable were subjected to an exploratory analytical test. Nine items were measuring entrepreneurial features as a determinant factor of growth for construction SMEs. The results revealed that the KMO of sampling adequacy as 0.791 suggesting that the sample size is indeed satisfactory for factor analysis. Conversely, Bartlett's Test of Sphericity undertaken established a high significance level of 0.00 as illustrated in Table 3. Also, the total initial eigenvalues greater than one were determined from the selected factor as depicted in the pattern matrix in Table 1.2.3.

Table 3: Entrepreneurial features of firm (EFF)

\begin{tabular}{lll}
\hline \multicolumn{2}{l}{ KMO and Bartlett's Test } & \\
\hline Kaiser-Meyer-Olkin Measure of Sampling Adequacy. & 0.791 \\
Bartlett's Test of Sphericity & Approx. Chi-Square & 740.762 \\
& Df & 36 \\
& Sig. & .000 \\
\hline
\end{tabular}

Source: Author's Compilation

Confirmatory Factor Analysis: A Confirmatory Factor Analysis (CFA) was employed carried out to determine the validity of the extracted factors regarding the convergent and discriminant validity of the construct in the study. Also, in contrast to the exploratory factor analysis (EFA), the Confirmatory factor analysis (CFA), is a more multifaceted and sophisticated set of techniques used in the study process to test (confirm) specific hypotheses or theories regarding the structure underlying a set of variables. Tabachnick and Fidell (2007) demonstrated that CFA is primarily pedestaled on sound empirical foundation or theories that permit an advance specification of the exact structure. Further, in CFA technique every observed variable has residual or errors associated the highlights the proportion of variance in the variable that is portrayed by the factors. Confirmatory factor analysis was, therefore, prudent and was adopted for assessing the factorial validity of this study. The CFA technique tested for reliability (Cronbach alpha and composite). Also evaluated was the reliability (Cronbach alpha and composite) and the validity (convergent and discriminate) using correlation matrix and the average variance extracted values in this study as represented in Tables (4) and (5).

Cronbach alpha and Composite Reliability: Cronbach's alpha is a measure of internal consistency, that is, how closely related a set of items are as a group. It is considered to be a measure of scale reliability Hair et al. (2010) stressed that values higher than 0.7 were considered as being reliable. Kipkebut (2010) also maintained that the values for Cronbach alpha range between 0 and 1 . In the context of this current study, the Cronbach Alpha value was 0.812 as shown in Table 4. Gliem and Gliem (2003: 87) supported that the closer Cronbach alpha is to 1.0, the more the internal consistency of the items in the scale. This also clarifies that the higher the alpha coefficient, the more reliable the test (Yu, 2001: 3). Similarly, a Composite Reliability analysis 
was carried out using SMART PLs software application. The test also examined the reliability of the construct and value of 0.857 was estimated as shown in Table 4.

Table 4: Reliability Analysis using Cronbach alpha and Composite Reliability

\begin{tabular}{|c|c|c|c|c|c|c|}
\hline Construct & & Code & $\begin{array}{c}\text { Factor } \\
\text { Loadings }\end{array}$ & $\begin{array}{l}\text { Number of } \\
\text { Items extracted }\end{array}$ & $\begin{array}{l}\text { Cronbach } \\
\text { alpha }\end{array}$ & $\begin{array}{l}\text { Composite } \\
\text { Reliability }\end{array}$ \\
\hline & & EFF 2 & 0.889 & & & \\
\hline Entrepreneurship & Features & EFF 3 & 0.842 & 3 & 0.812 & 0.857 \\
\hline
\end{tabular}

Source: Author's Compilation

Testing for Validity: In this study, the validity of the instrument was tested using the correlation matrix. The test was done using the factor loadings and the average value extracted. In measuring the Correlation matrix, the Average Value Extracted (AVE) as the Shared value, the convergent validity and the discriminant validity used in estimating the measurement validity. The discriminant validity of the study observed a comparison of the square root of the AVE for each construct and its relationship with other constructs. Fornell and Larcker (1981) stressed that for discriminant validity is be ascertained, the square root of the AVE for a construct must be greater than the correlation with the other constructs. Table (5) illustrates that the square root of all the AVE for each construct is greater than their correlations with other constructs showing that discriminant validity has been achieved. Further, the average variance extracted approximate reflects the total elements of variance in the indicators which accounted for by a latent construct. Fraering and Minor (2006), informs that an AVE value of 0.4 is seen as satisfactory. Hair et al. (2010) observed that a threshold value of 0.30 qualifies to be used as a minimum threshold in social sciences while in marketing discipline, an acknowledged threshold of 0.5 was comparatively acceptable. In the context of this study, limits ranging from 0.539 to 0.755 , which is consistent with that of Fraering and Minor (2006) and Hair et al. (2010) and are presented in Table (5).

Convergent validity: Hair et al. (2010) hypothesized that convergent validity is the extent at which indicators of a particular variable converge a high proportion of variance in common. This clarifies the extent at which a scale correlates with other measures of the same construct in the same direction. Carlsman and Herdman (2012) similarly supported that a weaker convergent validity is evident using values deviating from one while values closer to one is usually accepted. Table (5) presents the estimates of the factor loadings of Entrepreneurship features (EFF).

Table 5: Assessment of Average Variance Extracted (AVE)

\begin{tabular}{|c|c|c|c|}
\hline Research Construct & & Factor Loadings & AVE Value \\
\hline & EFF2 & 0.889 & \\
\hline Entrepreneurship features (EFF) & EFF3 & 0.842 & 0.750 \\
\hline
\end{tabular}

Source: Author's Compilation

Average value extracted (AVE): The Average Variance Extracted (AVE) approximately reflects on the total elements of variance in the indicators which accounted for a latent construct. Dillon and Goldstein (1984) suggested that an AVE value greater than 0.50 demonstrates that the convergent validity of the variable is satisfactory to be considered. According to Fraering and Minor (2006), an AVE value of 0.4 is realized as satisfactory. Hair et al. (2010) also observed that a threshold value of 0.30 qualifies to be used as a minimum threshold in social sciences while in the marketing field; an accepted threshold of 0.5 was comparatively acceptable. The study has a threshold of 0.750, which is consistent with that of Fraering and Minor (2006) and Hair et al. (2010) as presented in Table 5.

Measurement models for Entrepreneurial Features (EFF): Entrepreneurship features of a firm (EFF) as a construct to the growth of the firm in this current study demonstrated sufficient evidence regarding the measurement and reliability using the exploratory factor analysis (EFA). In ascertaining the construct's validity for the measurement models, a Confirmatory Factor Analysis (CFA) was carried out. Table (5) shows 
the Cutoff criteria for fit indices and the acceptable parameters. The study employed additional fit indices in assessing the viability of the current CFA model. These include CMIN or the Chi-square ( $\left.\mathrm{x}^{2} / \mathrm{df}\right)$, Normed Fit Index (NFI), Goodness-Of-Fit Index (GFI), the Root Mean Square Error of Approximation (RMSEA), TuckerLewis Index (TLI), Comparative Fit Index (CFI) as supported Incremental Fit Index as shown in Table (6). The chi-square index was checked as part of the CFA in determining the model fit of the study. The CMIN/DF recorded value of 2.094 as an acceptable value appropriate for the model. The value is consistent with Bentler and Bonet (1980:559) study, which suggested a chi-square value of less than $5(<5)$ for good model fit. The baseline comparison index was computed using the Normed Fit Index (NFI), Random fit index, the TuckerLewis Index (TLI), the Incremental Fit Index (IFI) as well as the Comparative Fit Index (CFI). Hair et al. (2010:672), a report on the chi-square value, either the CFI or the TLI and the RMSEA are expected to provide sufficient results for the model fit. In this study, all the indices were above 0.9 , which were strong enough to be accepted in the model fit. The Root Mean Square Error of Approximation was examined as part of the model fit, and it indicated a value of 0.058 as depicted in Table 6.

Table 6: Summary of Fit Indices of the Measurement Model

\begin{tabular}{lccl}
\hline \multicolumn{1}{c}{ Model Fit Indices } & $\begin{array}{l}\text { Acceptable } \\
\text { Threshold }\end{array}$ & Study Threshold & $\begin{array}{l}\text { Acceptable / } \\
\text { Unacceptable }\end{array}$ \\
\hline Chi-Square Value: $\chi 2 /(\mathrm{df})$ & $<3$ & 2.094 & Acceptable \\
Comparative Fit Index (CFI) & $>0.900$ & 0.932 & Acceptable \\
Incremental Fit Index (IFI) & $>0.900$ & 0.911 & Acceptable \\
Normed Fit Index (NFI) & $>0.900$ & 0.906 & Acceptable \\
Tucker Lewis Index (TLI) & $>0.900$ & 0.901 & Acceptable \\
$\begin{array}{l}\text { Random Measure of Standard } \\
\text { Error Approximation (RMSEA) }\end{array}$ & $<0.08$ & 0.058 & Acceptable \\
\hline Source: Authors Compiltion & & & \\
\hline
\end{tabular}

Source: Author's Compilation

The outcome of the fit indices of the initial assessment of the CFA of the variables and their indicators were all acceptable as shown in Table 6. The findings from the CFA exemplifies that the conceptual model was a representation of the collected data. Accordingly, once a good fit is obtained for a hypothesized model, the path significance of each relationship in the research model and the variance ought to be estimated, given that, the path modeling and its hypothesis test.

\section{Testing of Hypothesis}

Testing of the direct influence of Entrepreneurial Features on overall firm's growth: In testing the model hypothesis, the structural model is not its goodness of fit but also the achievability of the model. The statistical assessment of the values of factor loading and P-value for the indicator Entrepreneurial Features of Firm (EFF) revealed 3.046 and 0.002 respectively. The three values of the variables measuring the entrepreneurial features which further predict the endogenous variable firm growth was strong in predicting the endogenous variable (Table 5). This advocates that the relationship of these variables or indicators in determining the overall or integrated growth construction SME firms is major. Additional assessment of the variables of EFF indicated a significance level of 5 percent suggesting that the influence of the factor on the endogenous variable is direct and significant hence the proposition of the hypothesis was supported.

Table 6: Outcome from the Structural Model Testing

\begin{tabular}{lllll}
\hline Study's Hypothesis & $\begin{array}{l}\text { Hypothesis } \\
\text { Outcome }\end{array}$ & Loadings & P-Value & Remarks \\
\hline EFF & H1 & 3.046 & $0.002^{* * *}$ & Supported \\
\hline
\end{tabular}

Note: EFF: Entrepreneurial Features of Firm, FSG: Firm Growth, ${ }^{* * *} \mathrm{P}<0.01-0.05$

Source: Author's Compilation 
Findings and Discussions: Small and medium-size firms growth either by integration or organically as classified by Miriam (2006) is influenced by the entrepreneurial features and the environment where the firm operates. The entrepreneurial feature however of a firm is fundamental to firm's growth (Hashi and Kransnigi (2011). The features include personal entrepreneurial attributes of individual managing the firm, the level of knowledge on the business, the inherent culture within the firm. It has been argued that the entrepreneurial features of a firm which affect growth depend on the characteristics of the persons or the key persons providing the business capital. This is because the sponsors are the main risk takers and as a result have full control over their firm's operation. Zhou and Wit (2009) supported that owners will regarding sponsorship funding coupled with personal motivation influence growth of the firm. The activities SMEs globally are similar to the construction SMEs in Ghana. The characterized feature of this construction SMEs such as improper managerial structures, lack of succession plans, profit oriented, early liquidation soon after the execution of projects and low barriers to early which lead to the formation of inexperienced firms without any growth strategy. Despite the challenges of SMEs, firms categorised as SMEs are remarkably of impact equally on macro and the micro levels of an economy. Keskin and Senturk (2010) opined that SMEs contribute over 55 percent GPD in high-income economies and 70 percent in middle-level income nations while fulfilling employment, social, economic infrastructure development, and poverty reduction. Therefore, this implies that the sustainable growth of SMEs within a country is significant.

Firm's growth as defined by Miriam (2006) is influenced by internally or by integration. The internal or organic growth of a firm is largely influenced by the entrepreneurial features of the firm. A more vigorous analysis on the constructs that influence entrepreneurial features as a factor of growth of firm was embarked via EFA. Out of the nine constructs that were subjected to the analytical test only three constructs were found suitable for the next stage CFA. The explored constructs were justified by their reliability and validity values before the confirmatory analytical test. The established Cronbach alpha and composite reliability values were suitable, implying the constructs were reliable scales to predict the entrepreneurial feature as a subsequent determinant of firm growth. The validity of the explored constructs was tested using correlation matrix through the factor loadings. The discriminant validity of the constructs using their respective factor loadings fell within the certified values proposed by Fornell and Lacker (1981); this confirmed there was validity but discriminant. Convergent validity equally met the necessary thresholds which were inconsistent in the study of (Hiar et al., 2010). Before the measurement model of constructs for EFF, the validity of the constructs supported by the reliability was carried out. Also, to enable a viable model for the CFA several fit indices were made with their own cut off critical as depicted in Table (6). All the thresholds such as chi-square, normed fit index, GFI, RMSEA, TLI, and the CFI were found to be acceptable. The statistically tested hypothesis supported that there is a direct relationship between entrepreneurial features and firm growth. This further implies that, when adequate policies are established such as individual skills identification and development within the firm, it encourages intrinsic entrepreneurial ideas and foster firm's growth.

Implications of the study: The inference of this study to the construction SMEs is that entrepreneurial features as a determinant of firm's growth emanate from small individual skills which need to be developed. These skills must not essentially have to be that exhibited by the owner or sponsors of the firm. However, stakeholders (internal and external) skills must be explored in-line with the strategic goals and needs of the firm to help drive growth within the company.

\section{Conclusion}

This study established the explored constructs that influence entrepreneurial feature as a determinant of firm's growth among construction SMEs in Ghana. Despite the various identified challenges the construction SMEs sector in Ghana is faced, there are still important attributes from the sector that impact the entire Ghanaian economy. For instance, it was ascertained in the study by Keskin and Senturk (2010) that SMEs contributes over 55 percent GPD in high-income economies and 70 percent in middle-level income nations while fulfilling employment, social, economic infrastructure development, and poverty reduction. This therefore, affirms the imperative need of the SMEs. Extensive data of construction SMEs currently operating within the entire regional capital of Ghana was employed to estimate the influence of a variety of factors affecting SME growth. The statistical overview shows that there is a significant relation between entrepreneurial feature and firm's growth. The study justified this assertion by first exploring the various 
constructs using EFA. This followed by a CFA test which assessed both the reliability and validity of the constructs. The results of the reliability and validity assessment established that the constructs were suitable and in conformity with Hair et al. (2010). The CFA was also carried out to establish the construct's validity of the measurement models. The study as well adopted the acceptable parameters Cut-off criteria for fit indices including CMIN or the Chi-square ( $\mathrm{x}^{2} / \mathrm{df}$ ), Normed Fit Index (NFI), Root Mean Square Error of Approximation (RMSEA), Tucker-Lewis Index (TLI), Incremental Fit Index. Goodness-Of-Fit Index (GFI) as well as the Comparative Fit Index (CFI). These indices additionally made it more vigorous for the validity of the current CFA model to be assessed. The hypothesis was supported statistically that there is a direct relationship between entrepreneurial features and firm growth. The acceptance of the hypothesis was also supplemented by the three measurement variables namely: owner's strong entrepreneurial personality, (EEF2), strong desire to produce high standards (EFF3), strong human factor capital (EFF4) which indicated a high internal consistency measured the independent variable entrepreneurial features of the firm. The conclusion to this study further states that, when adequate policies are established such as individual skills identification and development within the firm, it encourages intrinsic entrepreneurial ideas and foster firm's growth. Entrepreneurial features of a firm how

Acknowledgment: An earnest appreciation is extended to all the respondent's firms that apportioned and devoted time to answering the questionnaire for this study. A further appreciation is to the dedicated team of the final year Building Technology students of Accra Technical University Ghana, who assisted in the questionnaire administration for this study.

\section{References}

Barringer, B. R. \& Bluedorn, A. C. (1999), The relationship between corporate entrepreneurship and strategic management. Strategic Management Journal, 20(5), 421- 444.

Bentler, P. M. \& Bonett, D. G. (1980), Significance tests and goodness of fit in the analysis of covariance structures. Psychological Bulletin, 88(3), 588.

Carlson, K. D. \& Herdman, A. O. (2012), Understanding the impact of convergent validity on research results. Organisational Research Methods, 15(1), 17-32.

Cassar, G. (2007). Money, money, money? A longitudinal investigation of entrepreneur career reasons, growth preferences and achieved growth. Entrepreneurship \& Regional Development, 19, 89-107.

Cliff, J. E. (1998). Does one size fit all? Exploring the relationship between attitudes towards growth, gender, and business size. Journal of Business Venturing, 13, 523-42.

Cooper, A. C., Gimeno-Gascon, F. J. \& Woo, C. Y. (1994). Initial human and financial capital as predictors of new venture performance. Journal of Business Venturing, 9, 371-395.

Delmar, F. \& Wiklund, J. (2008), The Effect of Managers' Growth Motivation on Firm Growth: A Longitudinal Study. Entrepreneurship: Theory and Practice, 3, 437 - 457

Dillon, W. \& Goldstein, M. (1984). Multivariate analysis: Methods and applications. New York: Wiley Publishers.

Ensley, M., Pearson, A. \& Amason, A. (2002). Understanding the dynamics of new venture top management teams: cohesion, conflict and new venture performance. Journal of Business Venturing, 17(4), 365-86.

Fornell, C. \& Larcker, D. F. (1981), Evaluating structural equation models with unobservable variables and measurement error. Journal of Marketing Research, 18(1), 39-50.

Fraering, M. \& Minor, S. M. (2006) The Virtcomm scale: A virtual community measurement tool. Chicago, IL: American Marketing Association Summer Educators Conference Proceedings.

Goedhuys, M. \& Veugelers, R. (2012), Innovation strategies, process and product innovations and growth: Firm-level evidence from Brazil. Structural Change and Economic Dynamics, 23, 516-529

Gliem, J. A. \& Gliem, R. R. (2003). Calculating, interpreting, and reporting Cronbach's alpha reliability coefficient for Likert-type scales. In $21^{\text {st }}$ Annual Midwest Research-to-Practice Conference on Adult, Continuing, and Community Education, 8-10 October. Columbus OH, 2003.

Gopinath, R. C. (2012). Understanding the determinants of firm growth in young REITs, Singapore.

Hair, J. F., Black, W. C., Babin, B. J., Anderson, R. E. \& Tatham, R. L. (2010). Multivariate data analysis with readings. 7 ed. Upper Saddle River, N.J: Pearson/Prentice Hall.

Hashi, I. \& Krasniqi, A. B. (2011) Entrepreneurship and SME growth: evidence from advanced and laggard transition economies. International Journal of Entrepreneurial Behavior \& Research, 17(5). 
Islam, M. A., Khan, M. A., Obaidullah, A. Z. M. \& Alam, M. S. (2011). Effect of entrepreneur and firm characteristics on the business success of small and medium enterprises.

Kaiser, F. H. (1970). A second generation little jiffy. Psychometrika, 35(4) $401-415$.

Keskin, H. \& Senturk, C. (2010). The importance of small and medium - sized enterprises SMEs in the economies: SWOT analyses of the SME sector in Turkey and Albani. Vol 3, Nr1, fq.116-132.

Kipkebut, D. J. (2010). Organizational Commitment and Job Satisfaction in Higher Educational Institutions: The Kenyan Case. PhD thesis, Middlesex University.

Kritikos, A. S. (2014). Entrepreneurs and their impact on jobs and economic growth, World of Labor Evidence-based policy making, IZA, Germany

Malhotra, N. K. (1999). Marketing research: An applied orientation $3^{\text {rd }}$ edition New Jersey Presentation Hall.

Miriam, J. (2006). Organic Vs Inorganic Growth: A case study, Dissertation Presentation for the Degree of MA in Finance and Investment.

Pajarinen, M., Rouvinen, P. \& Ylä-Anttila, P. (2006). Uusyrittä jien kasvuhakuisuus, KTM julkaisuja 29/2006. Helsinki: Ministry of Employment and the Economy

Papadakis, V., Lioukas, S. \& Chambers, D. (2000), Strategic decision-making processes: the role of management and context. Strategic Management Journal, 19, 115-147

Ruef, M., Aldrich, H. \& Carter, N. (2003). The structure of organisational founding teams: homophily, strong ties, and isolation among US entrepreneurs. American Sociological Review, 68(2), 195-222.

Shane, S. (2003). A General Theory of Entrepreneurship: The Individual-Opportunity Nexus. Cheltenham, UK: Edward Elgar.

Tabachnick, B. G. \& Fidell, L. S. (2007). Using multivariate statistics $5^{\text {th }}$ edition. Boston: Pearson Education.

Wiklund, J., Davidsson, P. \& Delmar, F. (2003). What do they think and feel about growth? An expectancyvalue approach to small business managers' attitudes toward growth. Entrepreneurship Theory \& Practice, 26(2), 247-70.

Yu, C. H. (2001). An introduction to computing and interpreting Cronbach coefficient alpha in SAS. In Proceedings of the 26th Annual SAS Users Group International Conference. North Carolina, 2001. SAS.

Zhou, H. \& de Wit, G. (2009). SCALES, Scientific Analysis of Entrepreneurship and SME's, Netherlands Ministry of Economic Affairs. 